\title{
EDAD AL PRIMER PARTO EN VACAS HOLSTEIN DE LECHERÍA ESPECIALIZADA EN COSTA RICA ${ }^{1}$
}

\author{
Mauren Salazar-Carranza ${ }^{2}$, Gloriana Castillo-Badilla², Jaime Murillo-Herrera ${ }^{3}$, Frank Hueckmann-Voss ${ }^{3}$, \\ Juan José Romero-Zúñiga
}

\section{RESUMEN}

Edad al primer parto en vacas Holstein de lechería especializada en Costa Rica. El objetivo de este trabajo fue determinar la edad al primer parto (EPP) en vacas Holstein puras en lecherías especializadas de Costa Rica. Se realizó un estudio longitudinal prospectivo histórico con 46029 animales de raza Holstein pura de lechería especializada de Costa Rica, durante el periodo comprendido entre los años 2000 y 2010. Se incluyeron los datos de vacas que contaban con registros completos para todas las variables del estudio, registrados en el programa VAMPP Bovino 3.0. Se calculó la EPP por las variables de zona ecológica, la época de nacimiento, el año de parto, el índice de endogamia, el número de lactancias de la madre y el tipo de parto que dio origen al animal en estudio. Los datos fueron analizados por medio de estadística descriptiva (porcentajes, promedios, desviación estándar [DE]) y el cálculo de intervalos de confianza (IC95\%)). La EPP promedio fue 30,7 meses (D.E: 6,8; IC 95\%: 30,6 - 30,8. Durante el periodo, el promedio de la EPP varió entre los 30 y 31 meses; sin embargo, en los años 2006 y 2007 mostró una tendencia a disminuir. La EPP presentó diferencias significativas entre estratos según la época de nacimiento, el número de lactancia de la madre, la zona ecológica, el año de nacimiento, el tipo de parto de la madre y el coeficiente de endogamia de la vaca. Al igual que las tendencias mundiales, mostró tendencia a decrecer en Costa Rica; y las variables de animal, tiempo y ambiente mostraron un efecto sobre la EPP. Excepto el coeficiente de endogamia (a mediano y largo plazo), esos factores no son modificables en condiciones de pastoreo, que son los imperantes en la gran mayoría de fincas estudiadas.

Palabras clave: vacas lecheras, coeficiente de endogamia, estrés calórico en vacas, registros computarizados en bovinos.

\begin{abstract}
Age at first calving in Holstein dairy cows specialized in Costa Rica. The objective of this work was to describe the age at first calving (AFC) of pure-bred Holstein cows in Costa Rica.A historical prospective longitudinal study with 46029 cows was conducted between 2000 and 2010. Data from cows with complete records for all study variables were included and reported in the 3.0 VAMPP Bovino program. The AFC were calculated by ecological zone, calving season, year of calving, inbreeding coefficient, lactation number of the dam and the type of calving that gave birth to the cow. The data were analyzed through descriptive statistics (percentages, mean, standar deviation $[\mathrm{SD}]$ and 95\% confidence intervals $[95 \% \mathrm{CI}]$. The average AFC was 30.7 months (SD: 6.8; 95\%CI: 30.6 - 30.8). During the period, the AFC ranged between 30 and 31 months; however, in 2006 and 2007, it tended to decrease. The AFC showed significant differences between strata according to the calving season and the lactation number of the dam; the ecological area, year of calving, type of birth and the inbreeding coefficient of the cow. As in global trends, the AFC showed a tendency to decrease in Costa Rica; and the variables animal, time and environment showed an effect on the AFC. Except for the inbreeding coefficient (medium and long-term), these factors are not modifiable under the grazing conditions that prevail in most of the studied farms.
\end{abstract}

Keywords: dairy cows, inbreeding coefficient, heat stress in dairy cows, computerized records in cattle.

\footnotetext{
Recibido: 13 de agosto, 2013. Aceptado: 28 de octubre, 2013. Este trabajo es parte de la tesis de licenciatura en Medicina Veterinaria de la primera autora. Escuela de Medicina Veterinaria de la Universidad Nacional, Heredia, Costa Rica.

2 Apdo. postal: 304-3000 Heredia. mausalazarcarranza@gmail.com, gcastiba@gmail.com

3 Cátedra de Salud de Hato y Control de la Producción, Escuela de Medicina Veterinaria, Universidad Nacional, Heredia, Costa Rica. Apdo. postal: 304-3000 Heredia. Teléfono: (506) 25624565. jmurillo80@gmail.com, huecsedo@hotmail.com, juan.romero.zuniga@una.cr (Autor para correspondencia).
} 


\section{INTRODUCCIÓN}

Con la globalización de la industria láctea y del comercio, es cada vez más importante reducir los costos de producción para lograr ser competitivos y, dentro de ello, el desarrollo adecuado de hembras de reemplazo es una inversión costosa para las fincas lecheras. Estimaciones de todos los gastos asociados con esta área específica son de aproximadamente el $20 \%$ del total de los costos de producción (Pirlo et al. 2000).

La edad al primer parto (EPP) consiste en el tiempo que tarda un animal en alcanzar su madurez sexual y reproducirse por primera vez (Hare et al. 2006), y refleja la velocidad de crecimiento de la hembra y la edad a la pubertad, cuya presentación tardía reduce el valor económico del animal al disminuir el número potencial de descendientes -y lactancias- producidos en su vida útil (Grajales et al. 2006).

La EPP puede ser influenciada por el tamaño corporal y el inicio de la actividad hormonal del sistema reproductivo (Moore et al. 1991). Aunque se considera que la edad a la pubertad no está determinada por un peso en particular, sí lo está por un orden indeterminado de condiciones fisiológicas que resultan de un peso dado (Grajales et al. 2006).

En los Estados Unidos de América, el promedio de EPP de las vacas lecheras (en su mayor parte Holstein), entre 1985 y 1990, fue de 25,9 meses (Pirlo et al. 2000). Actualmente, los programas de crianza de hembras para reemplazos tienen como meta que la edad promedio al primer parto sea de 24 meses, ya que esto implica una disminución en los costos de producción (Pirlo et al. 2000, Radostits 2003). Además, es esperable que a medida que se disminuya el EPP de una hembra, mayor será el número de terneros y leche producida por año de vida, por lo tanto, la productividad del hato también será mayor. Igualmente, Rodríguez et al. (1998) encontraron que la obtención del primer parto a una edad temprana ofrece ventajas; entre estas, un año más de vida reproductiva. Asimismo, Nilforooshan y Edriss (2004) afirman que la EPP puede afectar significativamente la producción de leche, el tiempo de vida y la vida productiva, ya que conforme aumenta la EPP, la vida productiva decrece. Así, al incrementar la EPP de 21 a 24 meses, la producción de leche aumentó, concluyendo que la edad óptima al primer parto para la producción de leche fue de 24 meses, y el retraso de EPP más allá de los 25 meses no es costo efectivo; de ese modo, se recomienda que las novillas tengan su primer cría entre 23 y 25 meses de edad (preferiblemente 24 meses).

Respecto a la respuesta reproductiva, Bouissou (1997) no encontró diferencias en los intervalos partoprimer servicio e intervalo parto-concepción entre las vacas que parieron a edad muy temprana y las que lo hicieron más tarde; aunque en el estudio de Marini et al. (2007) realizado en vacas Holstein de Argentina en sistema de pastoreo, las novillas de menor EPP, mostraron mayores intervalos reproductivos y no se diferenciaron significativamente de las de mayor edad en el número de servicios por concepción, concluyendo que la menor edad al primer parto no modifica la producción de leche pero afecta negativamente los indicadores reproductivos. Además, Ettema y Santos (2004), en su estudio realizado en California, indican que tanto la tasa de concepción a la primera inseminación postparto como los días abiertos fueron influenciados por la EPP, observándose una reducción de ambos parámetros en las vacas con una EPP media (23-25 meses) en comparación con las vacas con una EPP baja ( $<23$ meses) y alta ( $>25$ meses). También, la reducción de la EPP podría incrementar el número de terneros por vaca, pero podría traer consigo la dificultad de parto con la consecuente reducción en la viabilidad de los terneros, incrementando su susceptibilidad a infecciones debido a una reducida absorción de inmunoglobulinas (Pirlo et al. 2000). Además, conlleva a una reducción significativa de la fertilidad, incrementando los costos asociados a la reproducción, especialmente al intervalo entre partos y al descarte prematuro de animales valiosos (Moore et al. 1990).

Sin embargo, existen contradicciones en los hallazgos reportados por distintos autores acerca del efecto de la EPP sobre la producción de leche; algunos indican que un parto temprano es perjudicial para la producción de leche y la longevidad (Lin et al. 1986, Van Amburgh et al. 1998, Radcliff et al. 2000, Pirlo et al. 2000, Bormann et al. 2002, Ettema y Santos 2004, Nilforooshan y Edriss 2004, Marini et al. 2007). También, se dice que los programas de crianza de hembras para reemplazos tienen como meta que la edad promedio al primer parto sea de 24 meses, ya que esto implica una disminución en los costos de crianza y una más rápida recuperación de la inversión (Pirlo et al. 2000, Radostits 2003, Ettema y Santos 2004). 
La última investigación de tipo poblacional que se desarrolló en Costa Rica que involucró varias razas, incluyendo la Holstein, y de distintas zonas ecológicas, se realizó a mitad de los años noventa (Solano y Vargas 1997). El objetivo de este estudio fue describir la edad al primer parto (EPP) en vacas Holstein puras en lecherías especializadas de Costa Rica.

\section{MATERIALES Y MÉTODOS}

\section{Diseño y población de estudio}

Se realizó una investigación de tipo longitudinal prospectivo-histórico, utilizando datos de once años, entre el 1 de enero del 2000 y el 31 de diciembre del 2010. Se trabajó con los datos de 46029 vacas Holstein puras registradas en el programa VAMPP Bovino 3.0 (Noordhuizen y Buurman 1984) en el Centro Regional de Informática para la Producción Animal Sostenible (CRIPAS) de la Escuela de Medicina Veterinaria de la Universidad Nacional (EMV-UNA). Los hatos son de lechería especializados de Costa Rica.

\section{Recolección de datos y descripción de las variables}

Para esta investigación se utilizó la base de datos nacional de las fincas registradas en el programa VAMPP Bovino 3.0. Diariamente, en cada finca, los productores recolectan en una libreta de apuntes los datos de los eventos que ocurren. Posteriormente, esta información es introducida en el programa VAMPP Bovino 3.0 por ellos mismos o por técnicos que trabajan brindando asistencia en la granja. El personal del proyecto CRIPAS recolecta y centraliza, al menos dos veces al año, la información contenida en el programa VAMPP Bovino de cada finca, en forma descentralizada (Romero et al. 2000). Actualmente, VAMPP Bovino es utilizado por alrededor de 1500 fincas lecheras especializadas en Costa Rica, algunas con información de hace 30 años. Las variables que se utilizaron para la EPP se describen en el Cuadro 1.

El programa VAMPP Bovino 3.0 prosee un estricto sistema de control de calidad de ingreso de datos que asegura que al incluirlos en el programa sean biológicamente plausibles y fiables, de acuerdo con la condición del animal, basado en sus registros históricos (Rojas et al. 2011)

\section{Análisis de datos}

Los datos fueron extraídos de la Base Nacional de Datos VAMPP de CRIPAS en forma de un archivo ASCII, el cual fue editado utilizando el programa SAS versión 9.2 (SAS Institute Inc. 1990) en el que se eliminaron datos extremos que, aunque posibles, son poco plausibles biológicamente en sistemas de producción nacionales. En total, el porcentaje de datos eliminados no superó el $2 \%$.

El análisis de datos se realizó en dos fases: 1) Estadística descriptiva de las variables. En el caso de la EPP, se calculó medidas de tendencia central (media y mediana) y medidas de dispersión (DE); asimismo, se calcularon porcentajes en los estratos a las variables en su forma discreta. Para ambos tipos de medidas se determinó el intervalo de confianza (IC) al 95\%. 2) Para estimar el efecto de las variables independientes sobre la EPP, a cada variable se le calculó la media de la EPP en cada uno de sus estratos y se compararon utilizando sus respectivos intervalos de confianza al 95\%, además de una prueba para comparación de proporciones. Los análisis estadísticos se realizaron con el programa SAS versión 9.2 (SAS Institute Inc. 1990).

\section{RESULTADOS Y DISCUSIÓN}

El ingreso tardío de la hembra a pubertad y, consecuentemente a la vida productiva mediante su primer parto, redujo el valor económico de la vaca por la reducción en su vida productiva, la cantidad total de leche producida en su vida, así como en la disminución del número potencial de descendientes disponibles para remplazos (Botero 1990, Rodríguez et al. 1998, Nilforooshan y Edriss 2004, Grajales et al. 2006). De este modo, los programas de hembras de reemplazo tienen como meta que la edad promedio al primer parto (EPP) sea de 24 meses, ya que, además de las ventajas antes expuestas, implica una disminución en los costos de producción (Pirlo et al. 2000, Radostits 2003). Este ideal de EPP está muy lejana en las vacas analizadas en este estudio en que la EPP promedio para la población de estudio es de 30,7 meses (D.E: 6,8; IC95\%: 30,6 - 30,8) con una mediana de 28,9.

Este promedio es mayor a los reportados para la raza Holstein en países como Estados Unidos donde es de 25,9 meses (Heinrich et al. 1994), Italia de 26,0 
Cuadro 1. Descripción de las variables utilizadas en el análisis de la edad al primer parto de vacas Holstein puras, de hatos lecheros especializados de Costa Rica. Período 2000-2010.

\begin{tabular}{|c|c|c|c|c|}
\hline Variable & Condición & Tipo de variable & Nivel de variable & Descripción \\
\hline EPP & Dependiente & Politómica & $\begin{array}{l}\text { Bajo } \\
\text { Medio } \\
\text { Alto }\end{array}$ & $\begin{array}{l}<26 \text { meses } \\
\geq 26-<33,6 \text { meses } \\
\geq 33,6 \text { meses }\end{array}$ \\
\hline Año de nacimiento & Independiente & Discreta & Discreta & 2000-2009 \\
\hline $\begin{array}{l}\text { Época de nacimiento del } \\
\text { animal }\end{array}$ & Independiente & $\begin{array}{l}\text { Discreta } \\
\text { Dicotómica }\end{array}$ & $\begin{array}{l}\text { Seca } \\
\text { Lluviosa }\end{array}$ & $\begin{array}{l}\text { Diciembre- abril } \\
\text { Mayo-noviembre }\end{array}$ \\
\hline Tipo de parto de la madre & Independiente & $\begin{array}{l}\text { Discreta } \\
\text { Politómica }\end{array}$ & $\begin{array}{l}\text { Normal } \\
\text { Normal con RMF* } \\
\text { Distócico } \\
\text { Distócico con RMF } \\
\text { Cesárea }\end{array}$ & $\begin{array}{l}\text { Normal sin asistencia } \\
\text { Normal sin asistencia con RMF } \\
\text { Difícil con asistencia y sin cesárea } \\
\text { Difícil con asistencia sin cesárea y } \\
\text { con RMF } \\
\text { Difícil con asistencia y con cesárea }\end{array}$ \\
\hline Año del primer parto & Independiente & Discreta & Discreta & 2000-2009 \\
\hline Época de primer parto & Independiente & $\begin{array}{l}\text { Discreta } \\
\text { Dicotómica }\end{array}$ & $\begin{array}{l}\text { Seca } \\
\text { Lluviosa }\end{array}$ & $\begin{array}{l}\text { Diciembre-abril } \\
\text { Mayo-noviembre }\end{array}$ \\
\hline Zona ecológica** & Independiente & Discreta & & $\begin{array}{l}\text { bmh-P, bmh-T, bp-MB, bmh-M, bh- } \\
\text { MB, bh-P, bp-P, bh-T, bmh-MB (Ane- } \\
\text { xo 2). }\end{array}$ \\
\hline Endogamia & Independiente & Discreta & $\begin{array}{l}\text { Bajo } \\
\text { Alto }\end{array}$ & $\begin{array}{l}<6,25 \% \\
\geq 6,25 \%\end{array}$ \\
\hline
\end{tabular}

*RMF: Retención de membranas fetales.

**bp-MB= bosque pluvial montano bajo; bh-MB= bosque húmedo montano bajo; bh-P=bosque húmedo premontano; bh- $\mathrm{T}=$ bosque húmedo tropical; bmh- $\mathrm{MB}=$ bosque muy húmedo montano bajo; bmh- $\mathrm{P}=$ bosque muy húmedo premontano; bmh- $\mathrm{T}=$ bosque muy húmedo tropical.

meses (Pirlo 1997), Irán de 26,8 meses (Nilforooshan y Edriss 2004), España de 28,6 meses (Pérez et al. 1999) e incluso en Colombia de 26,72 meses (Bolivar et al. 2009). Sin embargo, el dato es similar al observado en trabajos anteriores realizados en fincas de Honduras y Costa Rica en los cuales fue de 29, $2 \pm 0,2$ meses (Moncayo 2004), en Argentina bajo condiciones de pastoreo fue de 31 meses $\pm 0,11$ (Marini et al. 2007) y en Egipto bajo condiciones semiáridas fue de 30,7 meses (Hammoud et al. 2010). Estas variaciones podrían ser atribuidas a condiciones nutricionales, climáticas y de manejo (El-Agawany y Hussein 1999).

La EPP fue dependiente de la ecozona donde se encuentra la vaca; se observaron dos grupos de ecozonas con EPP alta (entre 31 y 32 meses) y baja (entre 29 y 30), con diferencias estadísticas entre grupos y dentro de ellos. De ese modo, en el grupo de
EPP alta (bosque muy húmedo premontano [bmh-P], bosque muy húmedo tropical [bmh-T], bosque pluvial montano bajo [bp-MB], y bosque muy húmedo montano [bmh-M]), las zonas bmh-T y bm-MB fueron diferentes entre ellas. Por otra parte, el grupo de baja (bosque húmedo montano bajo [bh-MB], bosque húmedo premontano [bh-P] y bosque pluvial premontano [bp-P]), la bh-P fue diferente a las demás (Figura 1). Las ecozonas con EPP baja, corresponden a áreas de mayor altitud sobre el nivel del mar, con un índice de precipitaciones de 1200- $4000 \mathrm{~mm}$ /año y con una temperatura ambiental entre los $12-24^{\circ} \mathrm{C}$ (Cuadro 2). Dichas condiciones propician un adecuado crecimiento de forrajes, tales como el pasto Kikuyo (Pennisetum clandestinum) que en las zonas de altura de Costa Rica presenta un valor promedio de 22,6\% de proteína cruda, el cual es un valor considerado 


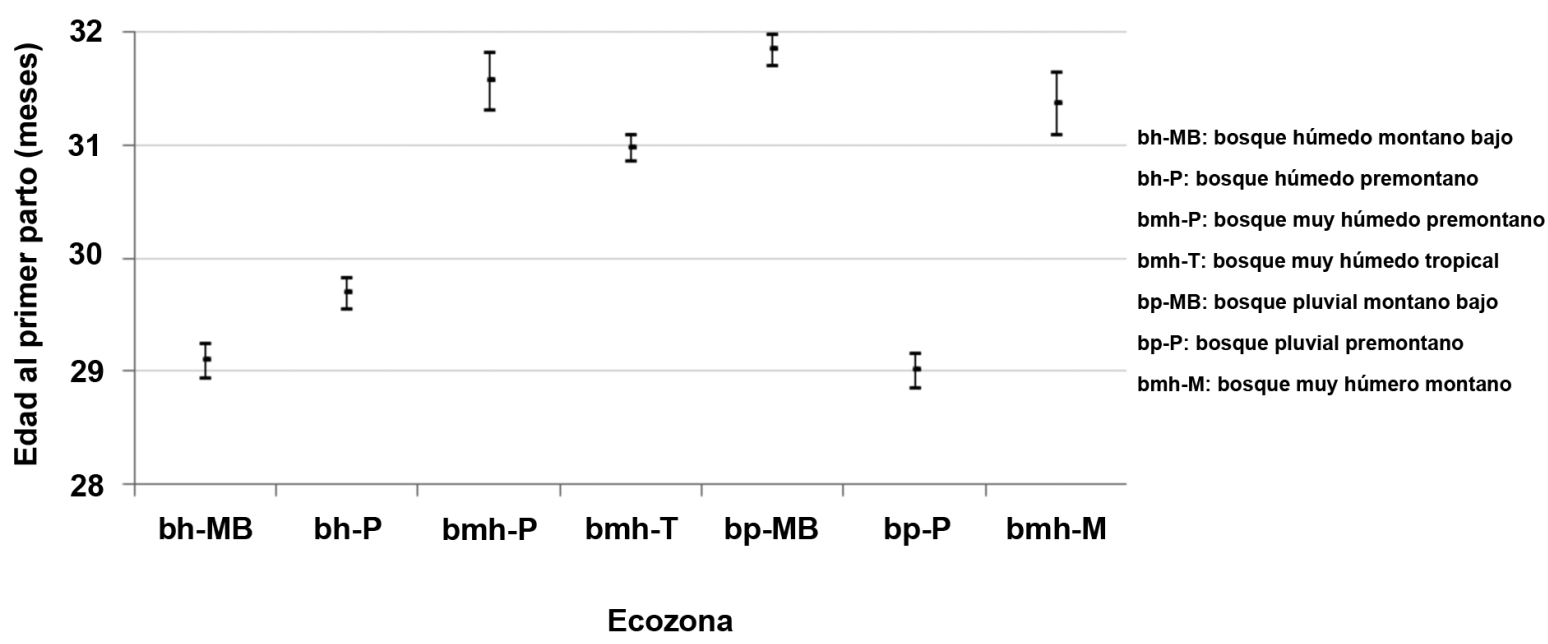

Figura 1. Edad al primer parto de vacas Holstein puras de hatos lecheros especializados de Costa Rica, según zona ecológica. Período 2000-2010.

alto para forrajes tropicales, favoreciendo así un buen desempeño productivo en la raza Holstein que proviene originalmente de zonas de clima templado. Asimismo, otros pastos como el Estrella africana (Cynodon nlemfuensis), San Juan (Setaria anceps) y Brachiaria ruzi (Brachiaria ruziziensis) en el trópico húmedo de Costa Rica presentan valores promedio de proteína cruda de $14,8 \%, 13,6 \%$ y $12,4 \%$, respectivamente (Cuadro 3).
Los forrajes tropicales se caracterizan por contener cantidades de energía inferiores y niveles de fibra superiores a los que poseen los forrajes de clima templado. Por el contrario, los animales ubicados en las zonas bmh- $\mathrm{P}$, bmh-T, bp-MB y bmh- $\mathrm{M}$ mantienen una EPP entre los 31-32 meses. Las zonas bmh-T y bmh-P se caracterizan por temperaturas elevadas y alta humedad relativa, con preponderancia de sistemas de pastoreo (Quesada 2007). Según el índice de humedad

Cuadro 2. Características de altitud, precipitación anual y temperatura media de las zonas de vida, según la clasificación de Holdridge (1987).

\begin{tabular}{lcccc}
\hline Zona & Código & Altitud (msnm) & $\begin{array}{c}\text { Precipitaciones } \\
(\mathbf{m m} / \mathbf{a n ̃ o})\end{array}$ & Temperatura $\left({ }^{\circ} \mathbf{C}\right)$ \\
\hline Bosque húmedo montano bajo & bh-MB & $1500-2000$ & $1000-2000$ & $12-17$ \\
Bosque húmedo premontano & bh-P & $500-1500$ & $1000-2000$ & $18-24$ \\
Bosque muy húmedo premontano & bmh-P & $500-1500$ & $2000-4000$ & $18-24$ \\
Bosque muy húmedo tropical & bmh-T & $0-500$ & $4000-8000$ & $>24$ \\
Bosque muy húmedo montano & bmh-M & $2000-2500$ & $1000-2000$ & $6-11$ \\
Bosque pluvial montano bajo & bp-MB & $1500-2000$ & $4000-8000$ & $12-17$ \\
Bosque pluvial premontano & bp-P & $500-1500$ & $4000-8000$ & $18-24$ \\
\hline
\end{tabular}

Fuente: Holdrige (1987) y Quesada-Monge (2007). 
Cuadro 3. Valor nutricional de los pastos del trópico húmedo de Costa Rica. Proteína Cruda (\% de la MS) y Energía Digestible (Mcal/kg de MS). Costa Rica. 2001.

\begin{tabular}{|c|c|c|c|c|}
\hline \multirow[t]{2}{*}{ Especie de pasto } & \multicolumn{2}{|c|}{ Proteína cruda } & \multicolumn{2}{|c|}{ Energía digestible } \\
\hline & Época semiseca & Época lluviosa & Época semiseca & Época lluviosa \\
\hline \multicolumn{5}{|l|}{ Zonas bajas tropicales } \\
\hline Estrella africana (Cynodon nlemfuensis) & 13,1 & 16,4 & 2,44 & 2,46 \\
\hline San Juan (Setaria anceps) & 15,3 & 11,8 & 2,65 & 2,46 \\
\hline Brachiaria ruzi (Brachiaria ruziziensis) & 13,5 & 11,2 & 2,48 & 2,38 \\
\hline King Grass (Pennisetum purpureum) & 8,4 & 9,6 & 2,15 & 2,09 \\
\hline \multicolumn{5}{|l|}{ Zonas altas } \\
\hline Kikuyo (Pennisetum clandestinum) & 22,0 & 23,2 & 2,89 & 2,98 \\
\hline
\end{tabular}

Fuente: Sánchez (2001).

y temperatura (ITH), cuando se alcanza valores superiores a 72 en el ITH, los cuales se obtienen a temperaturas $\geq 22^{\circ} \mathrm{C}$ y humedad relativa altas, el animal se encuentra en un estado de estrés calórico (Smith et al. 2006). El estrés calórico repercute directamente en el desempeño productivo del ganado, ya que afecta los mecanismos de termorregulación animal (evaporación, conducción, convección y radiación) (Collier et al. 2006), afectando su zona de confort o termoneutralidad $\left(5-25^{\circ} \mathrm{C}\right)$, lo que a su vez altera el consumo de alimento (West 2003), las concentraciones hormonales (Jordan 2003) y el metabolismo (Kadzere et al. 2002); por lo cual las condiciones presentes en estas zonas podrían contribuir a que se dé un retraso en la entrada a pubertad y consecuentemente la edad de primera concepción y parto. Estos resultados concuerdan con un estudio realizado en Costa Rica donde se observaron efectos altamente significativos de zona agroecológica $(\mathrm{P}<0,01)$ sobre la $\mathrm{EPP}$, donde las zonas donde se presentaron mayores EPP fueron bh-T y bs-T y la zona bh-MB presentó la menor EPP (Vargas y Ulloa 2008).

Durante el período de estudio se observan cambios estadísticos significativos en la EPP según el año de nacimiento de la vaca. El valor extremo más alto se registró en el año 1997 (34,7 meses) y el menor en 2008 (26,1 meses), con diferencias significativas de un año a otro desde el 2004 al 2007 (Figura 2). Ossa et al. (2007) y Hammoud et al. (2010) reportan que el año de nacimiento de la ternera fue una causa estadísticamente significativa $(\mathrm{P}<0,0001)$ de la variación de la edad al primer parto. Este efecto podría ser consecuencia de que las variaciones climatológicas que ocurren de un año a otro, repercuten en la fisiología propia del animal, así como también los cambios en los sistemas de alimentación (la cantidad y la calidad del forraje) y manejo de los hatos lecheros (Carvajal et al. 2002, Hammoud et al. 2010). Además, para el año 2008 se observó una marcada disminución de la EPP (media: 26,13 meses) con respecto a los anteriores; dicha diferencia podría ser atribuida a una menor cantidad de datos obtenidos para este año $(n=1279)$ en el programa VAMPP Bovino 3.0 consecuente a una falla en el reporte y envío de la información por parte de los productores de algunas fincas a la base nacional de datos en CRIPAS de la Universidad Nacional.

La época del año en que nació la hembra presentó asociación significativa sobre la EPP, aunque la diferencia fue de únicamente $+0,8$ meses (Cuadro 4). Así, en este estudio, los animales nacidos en época lluviosa, que salen a pastar entre los tres y seis meses de edad, según el sistema de crianza de cada finca, aprovecharían pastos de mayor calidad que aquellos animales nacidos en época seca (Sánchez 2001) y que salen a pastar en la época lluviosa (Cuadro 3). Hay que recalcar que una importante mayoría de hatos 


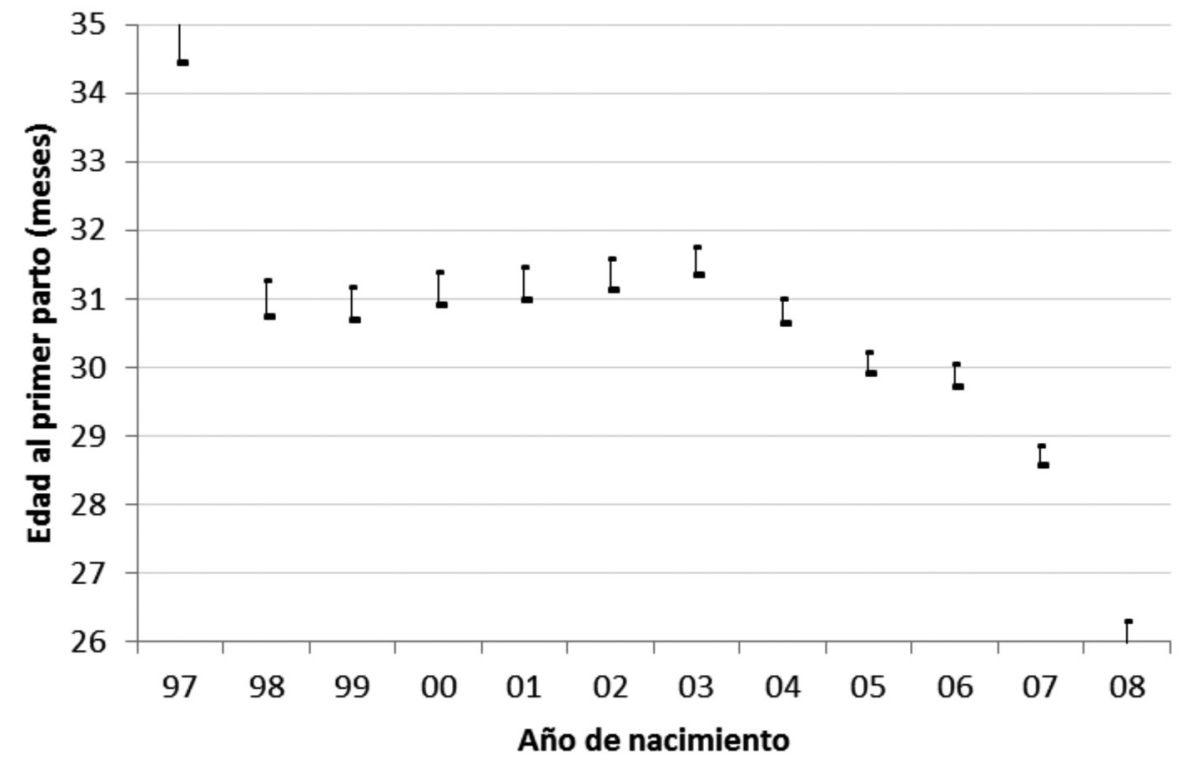

Figura 2. Edad al primer parto de vacas Holstein puras de hatos lecheros especializados de Costa Rica, según año de nacimiento del animal. Período 2000-2010.

crían en forma estabulada a las terneras hasta los tres o seis meses, en condiciones controladas, por lo que la diferencia la establecería la condición de los pastos, el clima y el manejo al momento de su salida a los pastos. Un estudio realizado en Colombia en animales de doble propósito (Ossa et al. 2007), constató un efecto significativo $(\mathrm{P}<0,001)$ del mes de nacimiento sobre la EPP, argumentando que los efectos provenientes del mes de nacimiento sobre la EPP pueden derivarse en parte, de las diferencias de alimentación en las épocas de verano e invierno las cuales, a su vez, se reflejan en el crecimiento y reproducción de las novillas.

Cuadro 4. Edad al primer parto de vacas Holstein puras de hatos lecheros especializados de Costa Rica, según variables de tiempo, lugar y animal. Período 2000-2010.

\begin{tabular}{lccccccc}
\hline Variable & Estrato & N & Media & DE & EE & & IC 95\% \\
\cline { 5 - 9 } & & & & & & LI & LS \\
\hline \multirow{2}{*}{ Época de nacimiento } & Seca & 21446 & 31,1 & 7,30 & 0,05 & 31,0 & 31,2 \\
& Lluviosa & 24583 & 30,3 & 6,32 & 0,04 & 30,2 & 30,4 \\
\hline \multirow{2}{*}{ Tipo de parto de la madre } & Normal & 45818 & 30,7 & 6,82 & 0,03 & 30,6 & 30,8 \\
& Distócico & 209 & 28,1 & 4,03 & 0,28 & 27,6 & 28,7 \\
\hline \multirow{2}{*}{ Coeficiente de endogamia } & $<6,25 \%$ & 33216 & 31,5 & 7,30 & 0,04 & 31,4 & 31,6 \\
& $\geq 6,25 \%$ & 12813 & 28,6 & 4,71 & 0,04 & 28,5 & 28,7 \\
\hline
\end{tabular}

D.E.= desviación estándar; EE= error estándar; IC95\%= intervalo de confianza al 95\%; LI= límite inferior, LS= límite superior. 
Asimismo, Casas y Tewolde (2001) indican que el efecto de época del año, además de la disponibilidad de alimento, está sujeto a otros factores como tolerancia a temperaturas ambientales elevadas y la eficiencia en la detección de celo; los cuales influyen en la expresión de características asociadas con la eficiencia reproductiva en condiciones tropicales.

A partir del segundo parto de la madre, la EPP promedio se mantuvo entre los 29 y los 30 meses, sin diferencias significativas; únicamente se observó un aumento significativo en la EPP en las hijas de vacas primerizas (31,5 meses) (Figura 3). La literatura es escasa en indicar si hay efecto del número de parto -de la madre- que dio origen a la hembra, sobre la EPP. En Venezuela según Sánchez y Martínez (2010) en vacas de doble propósito, el número de parto de la madre sí tuvo efectos significativos sobre la EPP. Berry et al. (2008), determinaron que existe un efecto de la madre sobre el rendimiento de su progenie, especialmente cuando se enfrenta a condiciones uterinas pobres que producen una alteración de la expresión genética del feto, como por ejemplo dietas insuficientes durante el periodo de gestación, que pueden provocar, debido a un balance negativo, bajos rendimientos productivos de las hijas. Por otra parte, al menos en Costa Rica en donde una amplia población de productores utilizan semen de animales de baja genética -e incluso monta natural- en novillas buscando poca dificultad de parto, especialmente en animales de pobre estructura corporal, es razonable pensar que los animales nacidos bajo estas condiciones sean de crecimiento un poco menor que los nacidos de vacas de segundo o más partos, que están más maduras y han sido probadas como productoras en las que se usa una mejor genética.

De 46029 registros, el 99,5\% (45818) de los animales nació mediante parto normal, llegando a una EPP de 30,7 meses (IC 95\%: 30,6 - 30,8), mientras que las hembras nacidas en un parto distócico mostraron una EPP de 28,1 meses (IC 95\%: 27,6- 28,7). Respecto a este factor la literatura es escasa; sin embargo, en al menos un par de estudios realizados anteriormente, el tipo de parto de la madre no ha sido asociado con variaciones en la EPP (Thompson et al. 1983, Ettema y Santos 2004).

Por otro lado, animales con coeficiente de endogamia $\geq 6,25 \%$, tuvieron una EPP $-2,9$ meses $(28,9$

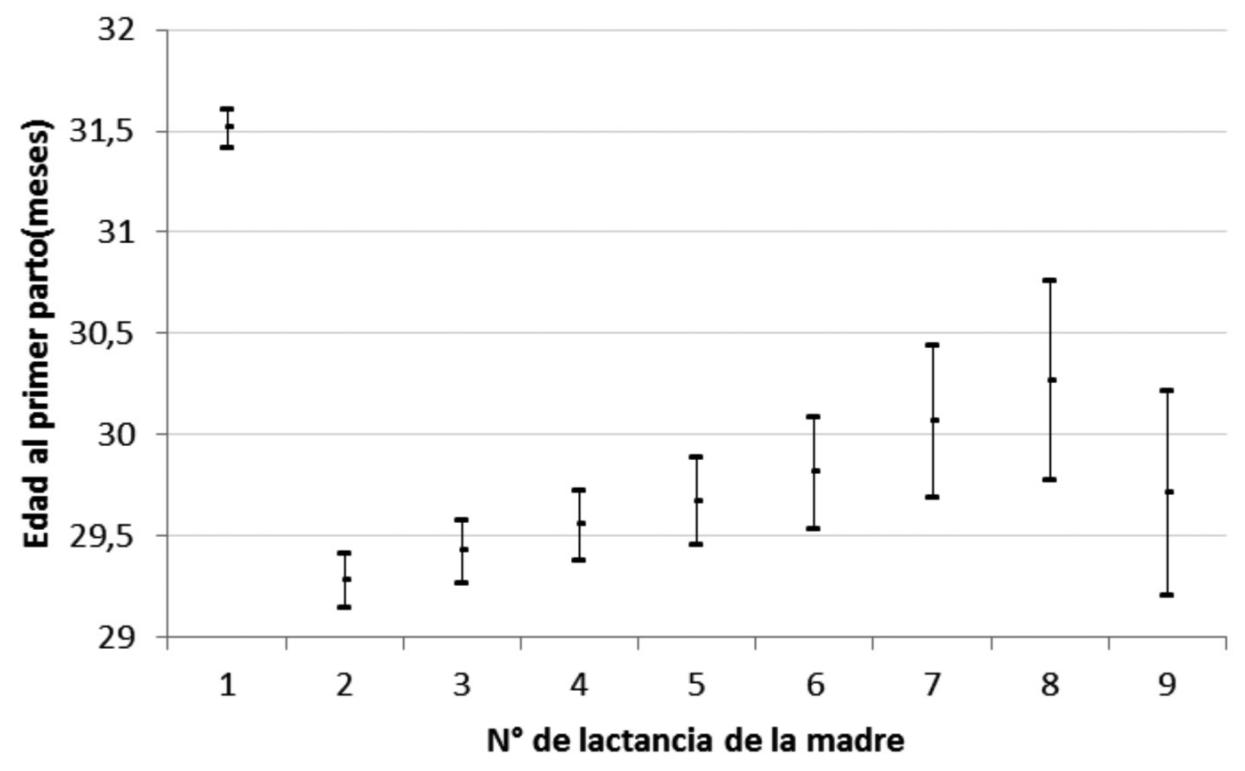

Figura 3. Edad al primer parto de vacas Holstein puras de hatos lecheros especializados de Costa Rica, según el número de lactancia de la madre. Período 2000-2010. 
meses: IC 95\%: 28,5- 28,7), con respecto a los individuos con un coeficiente de endogamia $<6,25 \%$ (30,7 meses: IC 95\%: 30,6 - 30,7) (Cuadro 4). Este resultado es contradictorio con recientes estudios que indican una asociación entre el aumento del nivel de consanguinidad y el incremento de la EPP (Vélez et al. 2002, McParland et al. 2007, Rokouei et al. 2010).

Así, conforme a las nuevas tendencias mundiales, la EPP mostró una tendencia a la baja en Costa Rica, sin alcanzar las medias observadas en países con lechería especializada. Asimismo, variables de animal, tiempo y ambiente mostraron un efecto sobre la EPP; lamentablemente, excepto el coeficiente de endogamia (a mediano y largo plazo) y mejoras en la nutrición y el manejo estratégico de los servicios (no analizados en esta investigación), el resto de factores no modificables en condiciones de pastoreo que son las imperantes en la gran mayoría de fincas estudiadas.

\section{AGRADECIMIENTOS}

A los productores de leche de Costa Rica que utilizan el programa VAMPP Bovino y que ofrecen sus datos a CRIPAS para realizar investigación poblacional. Asimismo, a la señorita Gina Isela Villegas por su colaboración en la revisión de estilo del documento final.

\section{LITERATURA CITADA}

Berry, DP; Lonergan, P; Butler, ST; Cromie, AR; Fair, T; Mossa, F; Evans, CO. 2008 Negative influence of high maternal milk production before and after conception on offspring survival and milk production in dairy cattle. J. Dairy Sci. 91(1):329-337.

Bolívar, DM; Echeverry, JJ; Restrepo, LF; Cerón, MF. 2009. Productividad de vacas Holstein y Jersey en una zona de bosque húmedo montano bajo (Bh-MB). Livestock Research for Rural Development 21(6): Article \#80 (en línea). Consultado 13 enero 2012. Disponible en http://www.lrrd.org/lrrd21/6/boli21080.htm

Bouissou, RG. 1997. Edad al primer parto. Marca líquida 64:41-44.

Bormann, J; Druet, T; Gengler, N; Wiggans, GR. 2002. Estimating effects of permanent environment, lactation stage, age, and pregnancy on test-day yield. J. Dairy Sci. 85(1):263.
Botero, L. 1990. Criterio para entrar novillas a toro. In II Seminario de producción agropecuaria. Mompox. p. 93-100.

Carvajal, M; Valencia, ER; Segura, JC. 2002. Duración de la lactancia y producción de leche de vacas Holstein en el Estado de Yucatán México. Revista Biomédica 13(1):25-31.

Casas, E; Tewolde, A. 2001. Evaluación de características relacionadas con la eficiencia reproductiva de genotipos criollos de carne en el trópico húmedo. Arch. Latinoam. Prod. Anim. 9(2):68-73.

Collier, R; Dahl, G; Van Baale, J. 2006. Major advances associated with environmental effects on dairy cattle. J. Dairy Sci. 89(4):1244-1253.

El Agawany, AA; Hussein, HM. 1999. Effect of climate on fertility of Holstein cattle in Egypt. J. Egyp. Vet. Med. Assoc. 59:1439-1465.

Ettema, J; Santos, J. 2004. Impact of age at first calving on lactation, reproduction, health, and income in FirstParity Holstein on Comemercial Farms. J.Dairy Sci. 87(8):2730-2742.

Grajales, H; Hernández, A; Prieto, E. 2006. Edad y peso a la pubertad y su relación con la eficiencia reproductiva de grupos raciales bovinos en el trópico colombiano. Livestock Research for Rural Development 18 (10) (en línea). Consultado 13 enero 2012. Disponible en http://www.lrrd.org/lrrd18/10/graj18139.htm

Hammoud, MH; El-Zarkouny, SZ; Oudah, EZM. 2010. Effect of sire, age at first calving, season and year of calving and parity on reproductive performance of Friesian cows under semiarid conditions in Egypt. Archiva Zootechnica 13(1):60-82.

Hare, E; Norman, H; Wright, J. 2006. Trends in calving age and calving intervals for Dairy cattle breeds in the United States. J. Dairy Sci. 89(1):365-370.

Holdrige, LR. 1987. Ecología basada en zonas de vida. 1 ed (tercera reimpresión). San José, Costa Rica, Instituto Interamericano de Cooperación para la Agricultura. $216 \mathrm{p}$.

Heinrichs, AJ; Wells, SJ; Hurd, HS; Hill, GW; Dargatz, DA. 1994. The national dairy heifers evaluation project: A profile of heifer management practices in United States. J. Dairy Sci. 77(6):1548-1555.

Jordan, E. 2003. Effects of heat stress on reproduction. J. Dairy Sci. 86 (supplement):104-114.

Kadzere, C; Murphy, M; Silanikove, N; Maltz, E. 2002. Heat stress in lactating dairy cows: a review. Livestock Production Science 77(1):59-91. 
Lin, CY; McAllister, AJ; Batra, TR; Lee, AJ; Roy, GL; Vesely, JA; Wauthy, JM; Winter, KA. 1986. Production and reproduction of early and late bred dairy heifers. J. Dairy Sci. 69(3):760-768.

Marini, PR; Charmandarian, A; Di Masso, RJ. 2007. Desempeño productivo y reproductivo de vacas de diferentes edades al primer parto en sistemas a pastoreo. Córdoba, Argentina (en línea). Consultado 15 enero 2012. Disponible en http://www.produccion-animal. com.ar/informacion_tecnica/cria/105-Marini.pdf

Moncayo, G. 2004. Evaluación del desempeño productivo y reproductivo de las razas Holstein, Pardo Suizo y sus cruces en dos fincas de Honduras y una de Costa Rica. Proyecto Especial de Ingeniero Agrónomo, Honduras. $29 \mathrm{p}$.

Moore, RK; Kennedy, BW; Schaeffer, LR; Moxley, JE. 1990. Relationships between reproduction traits, age and body weight at calving, and days dry in first lactation Ayrshires and Holsteins. J. Dairy Sci. 73(1):835-842.

Moore, RK; Kennedy, BW; Schaeffer, LR; Moxley, JE. 1991. Relationships between age and body weight at calving and production in first lactation Ayrshires and Holsteins. J. Dairy Sci. 74(1):269-278.

Nilforooshan, MA; Edriss, MA. 2004. Effect of age at first calving on some productive and longevity traits in Iranian Holsteins of the Isfahan Province. J. Dairy Sci. 87(7):2130-2135

Noordhuizen, J; Buurman, J. 1984. Veterinary automated management and production control program for dairy farms (VAMPP). The application of MUMPS for data processing. Veterinary Quarterly. 6(2):62-77.

Ossa, GA; Suárez, MA; Pérez, JE. 2007. Factores ambientales y genéticos que influyen la edad al primer parto y el intervalo entre partos en hembras de la raza criolla Romosinuano. Revista Corpoica - Ciencia y Tecnología Agropecuaria 8(2):74-80.

McParland, SM; Kearney, JF; Rath, M; Berry, DP. 2007. Inbreeding effects on milk production, calving performance, fertility, and conformation in Irish Holstein-Friesians. J. Dairy Sci. 90(9):4411-4419.

Pérez, MA; Hernández, D; Alenda, R; Carabano, MJ Charfeddine, N. 1999. Genetic analysis of true profit for Spanish dairy cattle. Interbull bulletin 23:107-113.

Pirlo, G. 1997. Rearing cost of replacement heifer and optimal age at first calving. L' Informatore Agrario 37:9-12.

Pirlo, G; Miglior, F; Speroni, M. 2000. Effect of age at first calving on production traits and on difference between milk yield returns and rearing costs on Italian holsteins. J. Dairy Sci. 83(3):603-608.

Quesada-Monge, R. 2007. Los bosques de Costa Rica. Memorias del IX Congreso Nacional de Ciencias: Exploraciones fuera y dentro del aula. Instituto Tecnológico de Costa Rica, Cartago. Ago. 24 y 25 (en línea). Consultado 15 enero 2012. Disponible en http://www.asvocr.org/pdfs/bosquedecostarica.pdf

Radcliff, RP; VandeHaar, MJ; Chapin, LT; Pilbeam, TE; Beede, DK; Stanisiewski, EP; Tucker, HA. 2000. Effects of diet and injection of bovine somatotropin on prepubertal growth and first-lactation milk yields of Holstein cows. J. Dairy Sci. 83(1):23-29.

Radostits, O. 2003. Herd heath: food animal production medicine. 3 ed. Pensilvannia, United States, W.B Saunders Company. 884 p.

Rodríguez, VA; Omar, V; Berbin, W; Rodríguez, M. 1998. El gen y formación del ganado tipo Yaracal. Comportamiento productivo y reproductivo. In Astro Data. SA. ed. Mejora de la ganadería mestiza doble propósito. Maracaibo, Venezuela. p. 121-134.

Rokouei, M; Vaez, R; Moradi, M; Sargolzaei, M; Sorensen, AC. 2010. Monitoring inbreeding trends and inbreeding depression for economically important traits of Holstein cattle in Iran. J. Dairy Sci. 93(7): 3294-3302.

Romero, JJ; Estrada, S; Pére, E. 2000. Uso del sistema de información VAMPP en investigaciones a gran escala In XVII Congreso Panamericano de Ciencias Veterinarias, 11-15 set, 2000. Ciudad de Panamá, Panamá. p. 101.

Rojas, J; Romero JJ; Estrada, S. 2011. VAMPP: un programa en constante evolución. Ventana Lechera 5(16):47-56.

Sánchez, JM. 2001. El valor nutritivo de algunos pastos tropicales de Costa (en línea). Programa de Registro y Control de Calidad de Alimentos para Animales, Convenio Universidad de Costa Rica (UCR) - Ministerio de Agricultura y Ganadería (MAG). Consultado 24 feb. 2012. Disponible en http://www. feednet.ucr.ac.cr/bromatologia/pcpt.htm

Sánchez, G; Martínez, G. 2010. Algunos factores no genéticos y de grupo racial que afectan la edad al primer parto en vacas doble propósito. Revista de la Facultad de Agronomía 36(3):125-133.

SAS (SAS Institute Inc., US). 1990. User's guide. Version 6. 4 ed. Cary, NC. 943 p.

Solano, C; Vargas, B. 1997. El crecimiento de novillas de reemplazo en fincas lecheras de Costa Rica: el efecto 
de la velocidad de crecimiento y edad al primer parto sobre la subsecuente producción de leche. Arch. Latinoam. Prod. Anim. 5(1):37-50.

Smith, T; Chapa, A; Willard, S; Herndon, C; Williams, R; Crouch, J; Riley, T; Pogue, D. 2006. Evaporative tunnel cooling of dairy cows in the southeast II: Impact on lactation performance. J. Dairy Sci. 89 (10):3915-3923.

Thompson, JR; Pollak, EJ; Pelissier, CL. 1983. Interrelationships of parturition problems, production of subsequent lactation, reproduction, and age at first calving. J. Dairy Sci. 66(5):1119-1127.

Van Amburgh, ME; Galton, DM; Bauman, DE; Everett, RW; Fox, DG; Chase, LE; Erb, HN. 1998. Effects of three prepubertal body growth rates on performance of Holstein heifers during first lactation. J. Dairy Sci. 81(2):527-538.

Vargas, B; Ulloa, J. 2008. Relación entre curvas de crecimiento y parámetros reproductivos en grupos raciales lecheros de distintas zonas agroecológicas de Costa Rica. Livestock Research for Rural Development 20(7) (en línea). Consultado 13 enero 2012. Disponible en http:// www.lrrd.org/lrrd20/7/varg20103.htm

Vélez, M; Hincapié, J; Matamoros, I; Santillán, R. 2002. Producción de ganado lechero en el trópico. 4 ed. Zamorano, Honduras, Escuela Agrícola Panamericana. $320 \mathrm{p}$.

West, J. 2003. Effects of heat-stress on production in dairy cattle. J. Dairy Sci. 86:2131-2144. 